\title{
Parent application of eutectic mixture of local anaesthetics seemed to be as effective as clinician application for reducing children's pain and distress during intravenous insertion
}

Koh JL, Fanurik D, Stoner J, et al. Efficacy of parental application of eutectic mixture of local anesthetics for intravenous insertion. Pediatrics 1999 Jun;103:1-5.

QUESTION: Is parent application of eutectic mixture of local anaesthetics (EMLA) as effective as clinician application for reducing children's pain and behavioural distress during intravenous (IV) insertion?

\section{Design}

Randomised (unclear allocation concealment), blinded (clinician) trial.

\section{Setting}

An outpatient gastrointestinal (GI) clinic in the US.

\section{Patients}

41 children of 2 age groups (younger group 5-12 y, mean age $9 \mathrm{y}$ and older group 13-18 y, mean age $15 \mathrm{y})$ who were scheduled for elective outpatient GI endoscopy with IV sedation. Children were excluded if they could not understand the visual analogue scale (VAS). Follow up was $88 \%$.

\section{Intervention}

After stratification by age group, children were allocated to parent $(n=11$ in the younger group, $n=10$ in the older group) or clinician $(\mathrm{n}=10$ in both the younger and older groups) application of EMLA (2.5 $\mathrm{g}$ to the back of both the child's hands, with occlusive covering) $\geq 60$ minutes before IV insertion.

\section{Main outcome measures}

Child reported pain from the IV insertion was measured on a $100 \mathrm{~mm}$ VAS (from no pain at all to the worst pain ever) and GI nurse observed child behavioural distress was measured on a 6 point scale $(0=$ not at all distressed, $5=$ extremely distressed) at 3 time points: anticipatory (behaviour from treatment room entry until the tourniquet was placed), insertion (behaviour at the time of the needle stick), and recovery (behaviour from taping of the IV until sedative medications were given).

\section{Main results}

Child reported pain and GI nurse reported child behavioural distress (anticipatory, insertion, and recovery) ratings did not differ by age or intervention group and were low to moderate for all groups (table).

Parent applied (PA) v clinician applied (CA) eutectic mixture of local anaesthetics in younger and older children

Source of funding:

no external funding.

For correspondence: DrJ L Koh,

Arkansas Children's Hospital, Pediatric Anesthesia and Pain Management, 800 Marshall St, Slot 203, Little Rock, $A R$

72202-3591, USA. Fax

+15013202939 .

\begin{tabular}{llllll} 
& $\begin{array}{l}\text { Median scores: } \\
\text { younger children }\end{array}$ & & \multicolumn{2}{c}{$\begin{array}{l}\text { Median scores: } \\
\text { older children }\end{array}$} \\
\cline { 2 - 3 } \cline { 5 - 6 } Outcomes & PA & CA & & PA & CA \\
$\begin{array}{c}\text { Anticipatory } \\
\text { behavioural } \\
\text { distress rating }\end{array}$ & 1.0 & 2.0 & & 1.0 & 1.0 \\
\hline $\begin{array}{c}\text { Insertion behavioural } \\
\text { distress rating }\end{array}$ & 1.0 & 2.5 & & 1.5 & 0.5 \\
\hline $\begin{array}{c}\text { Recovery } \\
\text { behavioural } \\
\text { distress rating }\end{array}$ & 0 & & & & \\
\hline Pain rating & 5.0 & 42.0 & 8.5 & 14.0 \\
\hline
\end{tabular}

\section{Conclusion}

Parent application of eutectic mixture of local anaesthetics seemed to be as effective as clinician application for reducing pain and behavioural distress during intravenous insertion in both younger and older children who were scheduled for elective gastrointestinal endoscopy.

\section{COMMENTARY}

The use of EMLA in children has been extensively reviewed in the literature and some researchers recommend that it should be applied before procedures by parents. ${ }^{1}$ Koh et al examined the effectiveness of parent application of EMLA in children and adolescents before IV insertion and found it to be as effective as clinician application. Strengths of this study are threefold: blinding of the GI nurse and anaesthesiologist by asking parents and children to avoid making statements about who applied the EMLA, equal distribution of younger and older children in both groups, and careful assessment of pain and distress.

A worrisome limitation of this study is the small sample size. When a study is designed to show equivalence between groups, the sample size must be large enough to avoid missing a clinically important difference. For example, median pain ratings in the younger age group were 5.0 in the parent applied group and 42.0 in the clinician applied group. On a 100 point pain scale, it is unlikely that a 37 point difference between groups would not be clinically significant and yet, the sample size of 10 per group was insufficient to find a statistically significant difference between these 2 medians. Differences between groups may have also been because of the fact that those in the parent application group were required to arrive 30 minutes before their scheduled procedure, whereas those in the clinician application group were required to arrive $\geq 60$ minutes before the procedure. The longer waiting times may have influenced anxiety in younger children in the clinician application group. No information was given about the site of IV placement, cannula size, or number of insertion attempts (which has been shown to positively correlate with the VAS). ${ }^{2}$

Parent application of EMLA, as supported in this study, could result in less time spent by families in the clinical setting; however, before suggesting implementation of this intervention, this study should be replicated with a larger sample.

David Anderson, RCPN

Pain Nurse Practitioner Anaesthetic Department Green Lane Hospital Auckland, New Zealand

1 Lander J, Hodgins M, Nazarali S, et al. Determinants of success and failure of EMLA. Pain 1996;64:89-97.

2 Robieux I, Kumar R, Radhakrishnan S, et al. Assessing pain and analgesia with a lidocaine-prilocaine emulsion in infants and toddlers during venipuncture. J Pediatr 1991;118:971-3. 